\title{
ANALISIS PEMBUATAN T-SHIRT DENGAN MESIN OVER LOCK BENANG 4 DAN BENANG 5
}

\author{
Sri Eko Puji Rahayu \\ Agus Hery Supadmi Irianti \\ Endang Prahastuti \\ Jurusan Teknologi Industri \\ Fakultas Teknik Universitas Negeri Malang \\ sriekopujirahayu@yahoo.co.id
}

\begin{abstract}
Abstrak
$T$ - Shirt, atau sering disebut dengan Kaos Oblong termasuk busana sehari-hari yang dapat dipergunakan, baik untuk santai dirumah, jalan-jalan maupun digunakan pada kesempatan non formal lainnya. T-Shirt, biasanya dibuat oleh industri busana baik yang skala kecil maupun oleh industri skala besar. T- Shirt dikerjakan dengan teknik jahit busana industri dan menggunakan mesin-mesin industri berkecepatan tinggi (High Speed). Mesin yang harus dipersiapkan diantaranya; mesin jahit setik lurus (High Speed), mesin obras (over lock) benang 4 dan benang 5, mesin kelim (overdeck). Mesin obras benang 4 dan 5 sama fungsinya, yaitu menjahit sekaligus merapikan tiras kain pada waktu yang bersamaan, namun hasilnya berbeda. Mesin obras benang 4 , hasil jahitan lurusnya berada pada tengah-tengah obras, sedangkan mesin obras benang 5 jahitan lurusnya 0,5 $\mathrm{cm}$ dari obras.

Jenis penelitian ini adalah penelitian deskriptif dengan pendekatan kuantitatif. Penelitian ini dimaksudkan untuk mendeskripsikan hasil analisis secara visual pembuatan T-Shirt berbahan kaos TC, Cardet dan Combed, dengan menggunakan mesin overlock benang 4 dan mesin overlock benang 5. Uji Validitas menggunakan Uji Validitas Konstruk dan Uji Reliabilitas menggunakan Test-Retest, sedangkan analisa data menggunakan statistik deskriptif.

Hasil penelitian pembuatan T-Shirt dengan mesin overlock benang 4, menunjukkan bahwa T-Shirt dengan bahan TC, $88,8 \%$ sesuai dengan standar produksi, bahan katun Cardet 94,\% sesuai dengan standar produksi, bahan katun Combed 86,6\% sesuai dengan standar produksi. Pembuatan T-Shirt dengan mesin overlock benang 5, menunjukkan bahwa T-Shirt dengan bahan TC, 89,7\% sesuai dengan standar produksi, bahan katun Cardet,96,9\% sesuai dengan standar produksi, bahan katun Combed, 91,8\% sesuai dengan standar produksi.

Kesimpulan dari penelitian ini adalah penggunaan mesin overlock benang 4 dan benang 5 memiliki standar produksi tertinggi pada bahan katun Cardet. Saran untuk penelitian berikutnya, sebaiknya analisis visual dibuat lebih terperinci lagi pada bagianbagian busananya, misal hasil jahitan pada bahu, kerung lengan, bagian sisi badan, dan kerung leher, karena tingkat kesulitannya yang berbeda-beda.
\end{abstract}

Kata Kunci: T-Shirt, Mesin Overlock

T- Shirt, atau sering disebut dengan Kaos Oblong merupakan busana yang sangat familiar dengan kehidupan kita sehari-hari, $T$ - Shirt termasuk busana sehari-hari yang dapat dipergunakan, baik untuk santai dirumah, jalan-jalan maupun digunakan pada kesempatan non formal lainnya. T-Shirt, merupakan busana yang dikerjakan dengan teknik jahit industri, baik industri busana yang berskala kecil maupun oleh industri berskala besar.

T- Shirt biasanya dihiasi oleh gambar-gambar atau tulisan yang disablon, bisa pada bagian muka full screen atau 
pada bagian belakang, lengan dsb. Teknik jahit busana industri, selalu menggunakan mesin-mesin industri yang berkecepatan tinggi (High Speed). Begitu pula dengan $T$ Shirt yang dikerjakan secara industri, yaitu; dikerjakan secara massal, dengan menggunakan ukuran standar, biasanya menggunakan label produksi, dan dengan teknik ban berjalan (Rahayu, 2008:18). Pada pembuatan busana industri terdapat berbagai macam mesin jahit berkecepatan tinggi, yang digunakan pada proses produksi, pada pembuatan $T$ - Shirt, mesin yang harus dipersiapkan diantaranya; mesin jahit setik lurus (High Speed), mesin obras (over lock) benang 4 dan benang 5 , mesin kelim (overdeck). Mesin obras (overlock) ada 3 macam, yaitu yang menggunakan benang 3 (untuk jahit rumahan, modiste/butik), benang 4 dan benang 5. Mesin obras benang 4 dan 5 sama fungsinya, yaitu menjahit sekaligus merapikan tiras kain pada waktu yang bersamaan, namun hasilnya berbeda. Mesin obras benang 4, hasil jahitan lurusnya berada pada tengah-tengah obras, sedangkan mesin obras benang 5 jahitan lurusnya $0,5 \mathrm{~cm}$ dari obras.

Hasil jadi dari pembuatan T-Shirt menggunakan kedua mesin overlock ini sepintas tampak sama jika dilihat dari bagian baik kain, mata orang awam tidak bisa membedakan apakah $T$ - Shirt ini dibuat menggunakan mesin overlock benang 4 atau mesin overlock benang 5 . Mengingat harga yang terpaut jauh, yakni mesin overlock benang 4 seharga Rp. 4.200.000 dan mesin overlock benang 5 seharga RP 12.000.000, sudah bisa dipastikan banyak industri busana yang menggunakan mesin yang lebih murah karena hasilnya sama. Selain efisiensi penggunaan benang pada kedua mesin Ovelock tersebut, karena jumlah benangnya yang berbeda, yaitu 4 dan 5 buah benang. Oleh karena perbedaan harga yang sangat jauh dan efisiensi penggunaan benang itulah yang mendorong peneliti ingin menganalisis hasil pembuatan $\mathrm{T}$ Shirt yang dibuat dengan menggunakan kedua mesin tersebut, dengan menggunakan jenis bahan kaos TC, Cardet dan Combed.

\section{Bahan Kaos Pembuatan T-Shirt}

Bahan yang biasanya

dipergunakan untuk pembuatan T-Shirt

ada bermacam-macam, beberapa diantaranya yang sering dipergunakan yaitu:

- TC (Tetoron Cotton); merupakan bahan kaos hasil penggabungan dari katun dan polyester, dengan komposisi $35 \%$ cotton combed dan $65 \%$ polyester. Bahan TC ini terasa panas jika dipakai karena kurang bisa menyerap keringat, namun kelebihan bahan ini lebih tahan kusut, dan tidak mulur meski sudah lama dipakai.

- Katun Combed; terbuat dari $100 \%$ serat kapas alami, memiliki tekstur yang halus, lembut dan nyaman dipakai, serta menyerap keringat (Lewis, 1960:265), sehingga sangat cocok dipakai di negara tropis, seperti Indonesia. Kain Combed merupakan kain yang banyak dipakai dan menjadi favorit produk Kaos distro.

- Katun Cardet; dibandingkan dengan Combed, katun Cardet memiliki serta benang yang kurang halus. Kain Cardet merupakan kain KW 1 nya Combed, sehingga hasil jahitan dan penampilannya kurang halus dan kurang rata, karena harganya yang relatif lebih murah dibandingkan Katun Combed. T-Shirt dengan bahan ini biasanya depergunakan untuk target pasar kelas menengah.

- Hyget; jenis bahan ini terbuat dari plastic yang sangat tipis, oleh karena itu harganya sangat murah. Bahan ini dapat dibilang 
kurang nyaman jika dibuat $\mathrm{T}$ Shirt, selain kurang nyaman karena tidak mengisap keringat, juga sulit pengerjaannya.

\section{Proses Pembuatan T-Shirt}

Proses pembuatan T-Shirt, dikerjakan dengan teknik jahit industri dan biasanya hanya industri busana baik yang skala kecil, menengah atau besar yang menerima order pembuatannya. Produksi T-Shirt tidak dapat menggunakan mesin jahit biasa, dan harus menggunakan mesin-mesin industri yang memiliki kecepatan tinggi. Proses produksi T-Shirt, meliputi

\section{a. Pattern and Marker}

Proses pembuatan pola dengan menggunakan ukuran standar, pecah pola sesuai dengan mode, dan menggrading pola serta merancang bahan dengan teknik marker, yaitu merancang bahan yang akan digunakan dengan jumlah banyak (skala besar/industri). Merancang bahan adalah menghitung berapa banyaknya bahan untuk membuat/memproduksi busana.

\section{b. Cutting}

Perencanaan produksi (tertib kerja) memotong (Cutting) produk busana, secara garis besar terbagi menjadi lima tahapan; yaitu:

1. Spreading, adalah proses membentangkan kain yang akan dipotong pada meja potong. Kain yang dibentangkan tersebut dapat mencapai puluhan lembar, sesuai dengan kapasitas mesin potong yang akan dipergunakan.

2. Cutting, adalah memotong bagian demi bagian pola yang tertuang dalam masing-masing Marker.

3. Numbering. adalah penomoran ikatan ukuran (size). Setiap 1 Size potongan diikat dan diberi nomor sesuai dengan urutan lembar Spreading/nomor Sizenya.

4. Bundling, adalah proses pengelompokan setiap bagian potongan menjadi suatu set pakaian, tujuannya adalah agar tidak ada bagian potongan yang tercecer dan memberikan tanda bila ada bagian yang memerlukan penanda (misal; lokasi saku, batas belahan dsb), sebelum di loading ke lini jahit (Sewing). Pada bagian tersebut dibubuhi penanda sesuai dengan tanda-tanda pada Marker.

c. Sewing

Agar proses menjahit (Sewing) dapat dilaksanakan dengan efisiensi yang maksimal, maka perencanaan atau tertib kerja menjahit harus dibuat terlebih dahulu. Potongan pakaian yang dikirim dari lini Cutting akan dikerjakan menurut tertib kerjanya dengan menggunakan sistem "ban berjalan", dengan sistem ini masing-masing sub lini hanya akan mengerjakan bagiannya sendiri-sendiri sesuai dengan ketrampilan dan dengan urutan jahitnya. Hasil jahitan yang dikerjakan dengan sistim ban berjalan akan lebih cepat dan hasilnya juga lebih rapi.

\section{d. Finishing}


Seluruh pekerjaan pada bagian finishing, meliputi; pressing, labeling, packing,

Mesin Obras (Overlock) Benang 4 dan Benang 5

Menurut Rahayu, (2010:8), mesin obras digunakan untuk merapikan tiras kampuh. Mesin obras untuk keperluan industri, ada yang menggunakan benang 4 dan ada yang menggunakan benang 5. Mesin ini digunakan untuk jahitan pengaman bahan dan dapat menggunakan 3 jarum sesuai dengan keperluan. Jumlah benang 3, 4, atau 5 yang membedakan hasil dari obrasan pada bahan. Benang 3 biasanya untuk jahitan modiste, butik atau rumah tangga, benang 4 untuk hasil jahitan yang berada pada tengahtengah obras, dan benang 5 untuk hasil jahitan yang terpisah antara setik lurus dan obrasnya. Mesin ini memiliki kecepatan kurang lebih 7000 rpm. Tipe jarum yang digunakan adalah DC x 27.

\section{Quality Control Pembuatan T-Shirt Dengan Mesin Overlock Benang 4 \& Benang 5}

Quality Control (pengendalian mutu) adalah semua usaha untuk menjamin agar hasil dari pelaksanaan sesuai dengan rencana yang telah ditetapkan dan memuaskan konsumen (pelanggan). Tujuan quality control adalah agar tidak terjadi barang yang tidak sesuai dengan standar mutu yang diinginkan (second quality) terusmenerus dan bisa mengendalikan, menyeleksi, menilai kualitas, sehingga konsumen merasa puas dan perusahaan tidak rugi. (Fitrihana, 2008)

Berdasarkan hal tersebut, proses produksi busana harus selalu mengawasi produksinya, agar tidak terjadi komplain dari konsumen. Salah satu pengawasan yang tidak kalah penting adalah, pengawasan terhadap hasil jahitan pada produknya. Penelitian ini akan menganalisis hasil pembuatan T-Shirt menggunakan mesin overlock benang 4 dan 5 tersebut. Hasil dari proses analisis tersebut akan dideskripsikan sesuai data yang diperoleh di lapangan., adapun indikator standar jahitan T-Shirt, dapat dilihat dari:

a. Jarak setikan konstan max $2 \mathrm{~mm}$ Yang dimaksud dengan jarak setikan konstan adalah, jarak lompatan benang jahit tetap dalam ukuran yang sama (max $2 \mathrm{~mm})$, tidak berubah-ubah mengecil atau menjadi lebih besar lagi, tuntas dari awal jahitan tidak berubah.

b. Kerapatan benang loop stabil Yang dimaksud dengan kerapatan benang loop stabil adalah, benang loop (aritan) memiliki jarak kerapatan yang sama, tidak ada yang lebih sempit atau lebih lebar.

c. Tidak terdapat kerutan pada bahan

Yang dimaksud tidak terdapat kerutan pada bahan yaitu, pada saat proses dan setelah proses sewing, bahan tidak berkerut yang biasanya terjadi karena tarikan benang tidak stabil.

d. Lebar benang loop atau aritan stabil

Yang dimaksud dengan lebar benang loop atau aritan stabil adalah, jarak lebar benang dari tepi kain ke dalam tidak berubah-ubah menjadi lebih sempit.

e. Benang lurus tidak melompat Yang dimaksud dengan benang jahit lurus tidak melompat adalah, jahitan benang katun harus masuk kebahan tiap $2 \mathrm{~mm}$, dan tidak pernah terjadi ada 
lompatan setik jahit yang $2 \mathrm{x}$ $2 \mathrm{~mm}$ atau lebih.

f. Benang loop tidak melayang Yang dimaksud dengan benang loop (aritan) tidak melayang adalah, kaitan benang aritan (loop) tidak lepas dari kaitan yang menyebabkan lompatanlompatan yang nampak pada tepi kain.

g. Tarikan benang katun dan polyester kuat/stabil

Yang dimaksud tarikan benang kuat dan stabil adalah tarikan kedua benang katun dan polyester sama tarikannya, tidak kuat salah satunya

h. Tidak ada benang yang putus Yang dimaksud tidak ada benang yang putus adalah, baik benang katun maupun polyester tidak ada yang terputus ditengah jalan, karena hal tersebut akan mengganggu proses produksi.

i. Hasil jahitan tidak kendur Yang dimaksud dengan jahitan tidak kendur adalah, tidak terdapat kelonggarankelonggaran pada semua tarikan setikan secara total.

j. Hasil jahitan bagian atas dan bawah sama bagusnya Yang dimaksud dengan hasil jahitan bagian atas dan bawah sama bagusnya adalah, selain jahitan yang rapat dan stabil bagian bawah bahanpun juga harus memiliki kerapihan yang sama dengan bagian baik/atasnya. Jarak setikan konstan max $2 \mathrm{~mm}$

k. Tidak ada benang yang menggumpal
Yang dimaksud dengan tidak ada benang yang menggumpal adalah, tidak adanya buhulbuhul benang yang tersimpul ditengah-tengah jahitan, karena selain mengganggu kualitas jahitan, juga mengurangi kerapihan penyelesaian jahitan.

\section{METODE PENELITIAN}

Penelitian ini dimaksudkan untuk mendeskripsikan hasil analisis pembuatan T-Shirt menggunakan mesin overlock benang 4 dan benang 5 , namun tidak bermaksud untuk membandingkan hasil produksi dari kedua mesin tersebut. Jenis penelitian ini termasuk kedalam penelitian deskriptif, tujuan utamanya, yaitu menggambarkan secara sistematis fakta dan karakteristik objek dan subjek yang diteliti secara tepat. Pada penelitian ini instrumen yang digunakan adalah kuesioner yang berbentuk check list, yang berisi pertanyaan dari jabaran indikator hasil pembuatan T-Shirt dengan jawaban Ya atau Tidak dan dianalisis dengan Deskripsi Persentase.. Kuesioner diberikan pada 3 orang panelis, yang menguasai teknik industri busana, masing-masing menilai 3 T_shirt dengan bahan TC, Katun Cardet dan Katun Combed.

\section{HASIL DAN PEMBAHASAN}

Hasil penelitian, analisis pembuatan T-Shirt dengan mesin overlock benang 4 dapat dilihat hasil dari Panelis 1,2 dan 3, menunjukkan bahwa T-Shirt dengan bahan TC; 90,9\%, 75,5\% dan 100\%. Hasil dari Panelis 1, 2 dan3, menunjukkan bahwa T-Shirt dengan bahan Katun Cardet; $84,5 \%$, 100\%, dan $100 \%$. Hasil dari Panelis 1, 2 dan 3, menunjukkan bahwa T-Shirt dengan bahan Katun Combed; $84,5 \%, 72,7 \%$, dan $100 \%$. (Lihat Tabel 1) 
Tabel 1 Tabulasi Angket Pembuatan T_Shirt dengan Mesin Overlock Benang 4

\begin{tabular}{|c|c|c|c|c|c|c|c|c|c|c|c|c|c|c|c|c|c|c|}
\hline \multirow{3}{*}{$\begin{array}{l}\mathbf{N} \\
\mathbf{O} \\
\end{array}$} & \multicolumn{6}{|c|}{ PANELIS I } & \multicolumn{6}{|c|}{ PANELIS II } & \multicolumn{6}{|c|}{ PANELIS III } \\
\hline & \multicolumn{2}{|c|}{ TC } & \multicolumn{2}{|c|}{ CARDET } & \multicolumn{2}{|c|}{ COMBED } & \multicolumn{2}{|c|}{ TC } & \multicolumn{2}{|c|}{$\begin{array}{c}\text { CARDE } \\
\mathbf{T}\end{array}$} & \multicolumn{2}{|c|}{ COMBED } & \multicolumn{2}{|c|}{ TC } & \multicolumn{2}{|c|}{$\begin{array}{c}\text { CARDE } \\
\mathbf{T}\end{array}$} & \multicolumn{2}{|c|}{ COMBED } \\
\hline & $\mathrm{Y}$ & $\mathrm{T}$ & $\mathrm{Y}$ & $\mathrm{T}$ & $\mathrm{Y}$ & $\mathrm{T}$ & $\mathrm{Y}$ & $\mathrm{T}$ & $\mathrm{Y}$ & $\mathrm{T}$ & $\mathrm{Y}$ & $\mathrm{T}$ & $\mathrm{Y}$ & $\mathrm{T}$ & $\mathrm{Y}$ & $\mathrm{T}$ & $\mathrm{Y}$ & $\mathrm{T}$ \\
\hline 1 & 10 & 1 & 10 & 1 & 9 & 2 & 11 & 0 & 11 & 0 & 8 & 3 & 11 & 0 & 11 & 0 & 11 & 0 \\
\hline 2 & 10 & 1 & 9 & 2 & 10 & 1 & 4 & 7 & 11 & 0 & 7 & 4 & 11 & 0 & 11 & 0 & 11 & 0 \\
\hline 3 & 10 & 1 & 9 & 2 & 9 & 2 & 10 & 1 & 11 & 0 & 9 & 2 & 11 & 0 & 11 & 0 & 11 & 0 \\
\hline$\Sigma$ & 30 & 3 & 28 & 5 & 28 & 5 & 25 & 8 & 33 & 0 & 24 & 9 & 33 & 0 & 33 & 0 & 33 & 0 \\
\hline $\begin{array}{c}\text { RT } \\
2\end{array}$ & 10 & 1 & 9,3 & 1,7 & 9,3 & 1,7 & 8,3 & 2,7 & 11 & 0 & 8 & 3 & 11 & 0 & 11 & 0 & 11 & 0 \\
\hline & $\begin{array}{c}90, \\
9\end{array}$ & $\begin{array}{c}9, \\
1\end{array}$ & $\begin{array}{c}84, \\
5\end{array}$ & $\begin{array}{c}15, \\
5\end{array}$ & $\begin{array}{c}84 \\
5\end{array}$ & $\begin{array}{c}15 \\
5\end{array}$ & $\begin{array}{c}75 \\
5\end{array}$ & $\begin{array}{c}24 \\
5\end{array}$ & 100 & 0 & $\begin{array}{c}72 \\
7\end{array}$ & $\begin{array}{c}27 \\
3\end{array}$ & $\begin{array}{c}10 \\
0\end{array}$ & 0 & 100 & 0 & $\begin{array}{c}10 \\
0\end{array}$ & 0 \\
\hline
\end{tabular}

Hasil penelitian, hasil penelitian pembuatan T-Shirt dengan mesin overlock 4 dapat dilihat hasil dari Panelis 1,2 dan 3, menunjukkan bahwa T-Shirt dengan bahan TC; 84,5\%, $84,5 \%$, dan $100 \%$. Hasil dari Panelis 1 ,

(Lihat Tabel 2)
2 dan3, menunjukkan bahwa T-Shirt dengan bahan Katun Cardet; 90,9\%, $100 \%$, dan $100 \%$. Hasil dari Panelis 1, 2 dan 3, menunjukkan bahwa T-Shirt dengan bahan Katun Combed; $100 \%$, $75,5 \%$, dan $\quad 100 \%$.

Tabel 2 Tabulasi Angket Pembuatan T_Shirt dengan Mesin Overlock Benang 5

\begin{tabular}{|c|c|c|c|c|c|c|c|c|c|c|c|c|c|c|c|c|c|c|}
\hline $\mathbf{N}$ & \multicolumn{6}{|c|}{ PANELIS I } & \multicolumn{6}{|c|}{ PANELIS II } & \multicolumn{6}{|c|}{ PANELIS III } \\
\hline & \multicolumn{2}{|c|}{ TC } & \multicolumn{2}{|c|}{$\begin{array}{c}\text { CARDE } \\
\quad \mathbf{T} \\
\end{array}$} & \multicolumn{2}{|c|}{$\begin{array}{c}\text { COMBE } \\
\text { D }\end{array}$} & \multicolumn{2}{|c|}{ TC } & \multicolumn{2}{|c|}{$\begin{array}{c}\text { CARDE } \\
\mathbf{T} \\
\end{array}$} & \multicolumn{2}{|c|}{$\begin{array}{c}\text { COMBE } \\
\text { D }\end{array}$} & \multicolumn{2}{|c|}{ TC } & \multicolumn{2}{|c|}{$\begin{array}{c}\text { CARDE } \\
\mathbf{T} \\
\end{array}$} & \multicolumn{2}{|c|}{$\begin{array}{c}\text { COMBE } \\
\text { D }\end{array}$} \\
\hline & $\mathrm{Y}$ & $\mathrm{T}$ & $\mathrm{Y}$ & $\mathrm{T}$ & $\mathrm{Y}$ & $\mathrm{T}$ & $\mathrm{Y}$ & $\mathrm{T}$ & $\mathrm{Y}$ & $\mathrm{T}$ & $\mathrm{Y}$ & $\mathrm{T}$ & $\mathrm{Y}$ & $\mathrm{T}$ & $\mathrm{Y}$ & $\mathrm{T}$ & $\mathrm{Y}$ & $\mathrm{T}$ \\
\hline 1 & 9 & 2 & 10 & 1 & 11 & $\mathbf{0}$ & 9 & 2 & 11 & $\mathbf{0}$ & 8 & 3 & 11 & $\mathbf{0}$ & 11 & $\mathbf{0}$ & 11 & $\mathbf{0}$ \\
\hline 2 & 10 & 1 & 10 & 1 & 11 & $\mathbf{0}$ & 9 & 2 & 11 & $\mathbf{0}$ & 9 & 2 & 11 & $\mathbf{0}$ & 11 & $\mathbf{0}$ & 11 & $\mathbf{0}$ \\
\hline 3 & 9 & 2 & 10 & 1 & 11 & $\mathbf{0}$ & 10 & 1 & 11 & $\mathbf{0}$ & 8 & 3 & 11 & $\mathbf{0}$ & 11 & $\mathbf{0}$ & 11 & $\mathbf{0}$ \\
\hline$\Sigma$ & 28 & 5 & 30 & 3 & 33 & $\mathbf{0}$ & 28 & 5 & 33 & $\mathbf{0}$ & 25 & 8 & 33 & $\mathbf{0}$ & 33 & $\mathbf{0}$ & 33 & $\mathbf{0}$ \\
\hline $\begin{array}{c}\text { RT } \\
2\end{array}$ & $\mathbf{9 , 3}$ & 1,7 & 10 & 1 & 11 & $\mathbf{0}$ & $\mathbf{9 , 3}$ & 1,7 & 11 & $\mathbf{0}$ & 8,3 & 2,7 & 11 & $\mathbf{0}$ & 11 & $\mathbf{0}$ & 11 & $\mathbf{0}$ \\
\hline & $\begin{array}{c}84, \\
5\end{array}$ & $\begin{array}{c}15, \\
5\end{array}$ & $\begin{array}{c}90, \\
9\end{array}$ & $\begin{array}{c}9, \\
1\end{array}$ & $\begin{array}{c}10 \\
0\end{array}$ & 0 & $\begin{array}{c}84, \\
5\end{array}$ & $\begin{array}{c}15, \\
5\end{array}$ & 100 & 0 & $\begin{array}{c}75, \\
5\end{array}$ & $\begin{array}{c}24, \\
5\end{array}$ & $\begin{array}{c}10 \\
0\end{array}$ & 0 & 100 & 0 & 100 & 0 \\
\hline
\end{tabular}

Berdasarkan hasil penelitian pembuatan T-Shirt dengan mesin overlock benang 5 , menunjukkan bahwa T-Shirt dengan bahan TC, $88,8 \%$ sesuai dengan standar produksi, bahan katun Cardet 94\% sesuai dengan standar produksi, bahan katun Combed $86,6 \%$ sesuai dengan standar produksi.
Pembuatan T-Shirt dengan mesin overlock benang 5 , menunjukkan bahwa T-Shirt dengan bahan TC, $89,7 \%$ sesuai dengan standar produksi, bahan katun Cardet,96,9\% sesuai dengan standar produksi, bahan katun Combed, 91,8\% sesuai dengan standar produksi. (Lihat Tabel 3)

Tabel 3 Rekapitulasi Hasil Kesesuaian Standar Produksi pada Pembuatan T-Shirt

\begin{tabular}{|c|c|c|c|}
\hline & Bahan Kaos TC & Bahan Katun Cardet & Bahan Katun Combed \\
\hline Overlock benang 4 & $88,8 \%$ & $94 \%$ & $86,6 \%$ \\
\hline Overlock benang 5 & $89,7 \%$ & $96,9 \%$ & $91,8 \%$ \\
\hline
\end{tabular}

Berdasarkan hasil temuan di lapangan, pembuatan T-Shirt yang menggunakan Mesin Overlock benang 4, dapat diinterpretasikan bahwa hasil yang memenuhi indikator standar jahitan yang paling baik adalah produksi $\mathrm{T}$ Shirt yang menggunakan bahan kaos
Katun Cardet, yaitu mencapai $94 \%$. Pembuatan T-Shirt yang menggunakan Mesin Overlock benang 5, dapat diinterpretasikan bahwa hasil yang memenuhi indikator standar jahitan yang paling baik adalah produksi $\mathrm{T}$ Shirt yang menggunakan bahan kaos 
Katun Cardet, yaitu mencapai 96,9\%. Mesin Overlock, baik yang benang 4 maupun benang 5 memiliki pisau yang tajam, jika dipergunakan pada bahan TC sering menyebabkan benang putus. Pada bahan katun Cardet, jahitan lebih stabil, karena karakter bahan yang lebih padat dan rapat, sedangkan pada bahan Combed, karena karakter bahan agak lunak/lemas, sebaiknya pisau obras yang tajam, karena kalau tumpul akan menyebabkan benang menggumpal.

\section{KESIMPULAN}

Penggunaan mesin Overlock benang 4 dan benang 5 memiliki standar jahitan yang terbaik pada bahan katun Cardet (94\% dan 96,9\%). Bahan katun ini, meskipun memiliki benang yang kurang halus, karena katun Cardet merupakan kain yang kualitasnya dibawah katun Combed, namun hasil jahitannya relatif lebih bagus dan stabil dibanding bahan yang lain. Bahan kaos Cardet ini hasilnya juga kurang maksimal jika di painting atau di sablon, dibandingkan dengan bahan katun Combed yang 100\% berasal dari katun.

Saran untuk penelitian berikutnya, sebaiknya analisis visual dibuat lebih terperinci lagi pada bagianbagian busananya, misal hasil jahitan pada bahu, kerung lengan, bagian sisi badan, dan kerung leher, karena tingkat kesulitannya yang berbeda-beda.

\section{DAFTAR PUSTAKA}

Arikunto, Suharsimi. 2006. Prosedur Penelitian Suatu Pendekatan Praktik (edisi revisi). Jakarta : PT Rineka Cipta.

Fitrihana. Noor. 2008. Quality Control di Industri Garmen. Jogyakarta: Pelatihan QA Garmen

Eny, Maftukhah. Garment studionline.blogspot.com, diakses tanggal 17 Mei 2016

Lewis, Dora. S. 1960. Clothing Construction and Wardrobe Planning. New York: The Macmillan Company

Rahayu, SEP. 2015. Modul: Teknik Pembuatan Busana Industri. Malang: FT Universitas Negeri Malang.

Rahayu, SEP. 2010. Pengetahuan dan Pemeliharaan Alat Jahit. Malang: FT

Universitas Negeri Malang

Rahayu, SEP. 2008. Teknik Pembuatan

Busana Industri. Malang: FT

Universitas

Negeri Malang

Saldias. Andres. Tanpa tahun. Quality

Management System For

Indonesian Garment Factories. Senada Consultant

Yulianto, Tantan. 2010. Apa arti T pada T-Shirt?. https://turtlemotion.wordpress.c om, diakses tanggal 17 Mei 2016 